\title{
FLOWER COLOUR POLYMORPHISM IN CIRSIUM PALUSTRE
}

\section{POLLINATION}

\author{
D. J. MOGFORD \\ The Botany School, South Parks Road, Oxford OXI 3RA
}

Received 17.xii.73

\begin{abstract}
SUMMARY
The white flowered morph of Cirsium palustre (L.) Scop. is subject to preferential pollination. Since the polymorphism is localised in regions which are likely to possess a low pollinator activity it is suggested that the polymorphism may be an adaptive response to conditions of low pollination.
\end{abstract}

\section{INTRODUCTION}

A PREvious paper (Mogford, 1974) described how the typically purple flowered Cirsium palustre (L.) Scop. exhibits white and intermediate flowered forms in high frequency in seacliff and mountain populations, and how this variation constitutes a polymorphism subject to selective forces associated with exposure and fluctuation in population size. In this paper is discussed how the occurrence of the polymorphism may be related to the degree of cross-pollination.

\section{Glimatic influences upon pollination}

The flowers of $C$. palustre possess colour, fragrance, nectar, and an irritability mechanism of the anthers (Small, 1917), and are visited in favourable habitats by such an abundance of insect visitors as to appear largely outcrossing. Müller recorded the visits of 39 insect species, which included Coleoptera, Diptera, Hymenoptera and Lepidoptera (Müller, 1883; Knuth, 1908). However, the species is self-compatible, and in the Faroe Islands, where pollinating insects are scarce, appears to be largely autogamous (Hagerup, 1951). Moreover, although the occurrence of at least partial outbreeding in seacliff populations was indicated by the presence of non-white individuals in the progeny of white plants subject to natural pollination in certain Gower populations (Mogford, 1974), it remained that both seacliffs and mountains possessed climatic conditions likely to reduce the degree of insect pollination. Both regions were subject to high exposure, while mountains were in addition subject to low temperatures and large amounts of mist and rain. Such conditions produce diminution in both pollinator activity (Wilson, 1929; Miyamoto, 1960; Eisikowitch and Galil, 1971; Heinrich, 1972) and total pollinator population (Hagerup, 1950, 1951). Of direct relevance are the remarks of Willis and Burkill (1895, 1903) and Proctor and Yeo (1973) on the scarcity of pollinating insects on British mountains.

In conditions of limited pollination particular importance would attach 
to any differences between the morph types in self-compatibility or attractiveness to pollinators. These possibilities were therefore examined.

\section{Self-compatibility}

These determinations were performed in 1968 on plants from Wentwood in Monmouthshire and Clyne Common in Gower, and in 1971 on plants derived from pollinations performed in 1969 on plants from the latter population. For each set of plants selfings and crossings were conducted in the manner described previously (Mogford, 1974), and the percentage viability of the achenes measured. This was performed by visual separation of the firm, fully developed achenes from the shrivelled, aborted achenes; the former gave almost complete germination on moist filter paper and were therefore assumed to be fully viable. The results are shown in table 1 .

TABLE 1

Seed viability in artificial pollinations

\begin{tabular}{|c|c|c|c|c|c|}
\hline \multirow[b]{2}{*}{ Morph Type } & \multirow[b]{2}{*}{ Pollination } & \multirow[b]{2}{*}{ Population } & \multirow[b]{2}{*}{ ' $n$ ' } & \multicolumn{2}{|c|}{$\begin{array}{l}\text { Viability, } \\
\text { degrees }\end{array}$} \\
\hline & & & & Mean & S.E. \\
\hline Total morphs & Selfing & Clyne 1968 & 6 & $35 \cdot 48$ & $6 \cdot 11$ \\
\hline Total morphs & Crossing & Clyne 1968 & 28 & $53 \cdot 10$ & $2 \cdot 53$ \\
\hline Total morphs & Selfing & Wentwood 1968 & 18 & $22 \cdot 35$ & 3.41 \\
\hline Total morphs & Crossing & Wentwood 1968 & 21 & $46 \cdot 92$ & $3 \cdot 44$ \\
\hline Purple & Selfing & Clyne 1969 progeny & 31 & $34 \cdot 08$ & 1.98 \\
\hline White & Selfing & Clyne 1969 progeny & 22 & $32 \cdot 77$ & $3 \cdot 31$ \\
\hline $\begin{array}{l}\text { Total morphs } \\
\text { (progeny of selfing) }\end{array}$ & Selfing & Clyne 1969 progeny & 40 & $34 \cdot 94$ & $2 \cdot 48$ \\
\hline $\begin{array}{l}\text { Total morphs } \\
\quad \text { (progeny of crossing) }\end{array}$ & Selfing & Clyne 1969 progeny & 23 & $29 \cdot 06$ & $2 \cdot 24$ \\
\hline
\end{tabular}

It was found from the 1971 results that the purple and white morph types did not differ significantly in self-compatibility. In both the Clyne and Wentwood plants tested in 1968 the proportion of viable seed set by selfing was significantly lower than that set by crossing. Neither proportion was significantly different between populations. The self-compatibility of the 1971 plants derived by selfing did not differ significantly from that of those derived by crossing or from that of the parental population tested in 1968 .

Examination of the natural seed production in four populations on the Gower Peninsula indicated that the percentage viability of the ovules did not differ significantly between morph types within populations, but showed slight, though significant, differences between populations, varying from $84 \cdot 8$ to $91 \cdot 7$ per cent (Mogford, 1972).

\section{Discriminative pollination}

During the summer of 1971 a series of experiments revealed that the movements of bees upon $C$. palustre were very precise with respect to both the morph types visited and the direction of foraging. The present account is 
devoted to the former topic, directionality during foraging having been treated elsewhere (Mogford, 1972).

\section{(i) Method}

The experiments were based on a comparison of the ratio of morph types present in a population with the ratio of morph types visited in the population by a particular category of forager. For a large number of visits a significant difference between these ratios will be a consequence only of either colour discrimination or a non-random distribution of foragers. The distribution of foragers could be assumed to be random since the plants were fairly uniform in size and flower production, and the distances travelled by individual pollinators were of comparable magnitude to the areas of population studied. Accordingly the difference between the above ratios was taken as a measure of colour discrimination.

The populations studied comprised a seacliff population on the Gower Peninsula (Rhossili Down) and five mountain populations on the Brecon Beacons. At each population observations were conducted within a marked area enclosing several hundred plants. The total number of plants of each morph type within the area was counted and the visits of foragers to individual plants recorded. Normally a minimum of 500 visits were recorded for each category of forager considered. Individual foragers were followed for as long as possible in order to reduce human bias in the choice of plants. At hourly intervals the total number of foragers of each type studied present within the enclosed area was scored using marked rows as an aid to counting.

Observations were confined to bee species since these were overwhelmingly the most important daytime pollinators. In the Gower population both honeybees and bumblebees were present, but in the mountain populations honeybees were completely absent. Recordings were conducted separately on the different bee species present and in some cases on the different sexes present. At each population the great majority of the bees present belonged to a comparatively small number of species and accordingly observations were restricted to the common species in each case. Night pollination was not studied since by the onset of darkness all pollination had virtually ceased, although such might have been significant at least at Rhossili Down where moths were occasionally seen on the flowers during late evening.

\section{(ii) Results}

The significance of the degree of discrimination displayed by each bee type was calculated separately for each morph type in each population. The tests were performed using $\chi^{2}$ to assess the difference between the observed and expected values for the ratio of the number of morphs of a particular type visited to the total number of alternative morphs present in each population.

The results are shown in table 2. It was found that discriminative pollination was a frequent phenomenon and in most cases involved preferential pollination of the white morphs. Thus of the 12 cases in which pollination of the white morphs was studied, six involved their preferential pollination and in no case were they discriminated against. In contrast, of the 21 cases in which pollination of the purple morphs was studied, only one 
TABLE 2

Preferential pollination

Morph and visits ratios

Discrimination probability

$\overbrace{\mathbf{P} \quad \mathrm{I} \quad \mathrm{ppW} \quad \mathrm{W} \quad{ }_{n}} \overbrace{\mathrm{P} \quad \mathrm{I} \quad \mathrm{ppW} \quad \mathrm{W}} f \%$

(a) Mynydd Llangattwg (SO 159166)

Morph ratio

$B$. agrorum

B. lapidarius

(o)

B. lapidarius

()

B. lucorum

Morph ratio

B. agrorum

B. lapidarius

(ठ)

B. lapidarius

(9)

B. lapponicus

B. lucorum

Morph ratio

B. pratorum

(q)

Morph ratio

A. mellifera

$76 \cdot 7$

$71 \cdot 4$

$66 \cdot 5$

$0.4 \quad 32 \cdot 7$

$32 \cdot 7$
$32 \cdot 3$

0.4

$0 \cdot 1$

245

67.5

$63 \cdot 6$

$75 \cdot 4$

$53 \cdot 5$

0.0

$0.0 \quad 24 \cdot 6$

$0.0 \quad 46.5$

$0 \cdot 0$
$0 \cdot 0$
$0 \cdot 0$

671

N.S. -

N.S. -

$79 \cdot 1$

(b) Mynydd Troed (SO 171295)

$\begin{array}{crr}\text { (b) } & M & \\ 21.7 & 0.7 & 678\end{array}$

$\begin{array}{lllll}61.3 & 16.2 & 21.7 & 0.7 & 678 \\ 58.0 & 18.7 & 22.8 & 0.5 & 653\end{array}$

$65 \cdot 2$

$16 \cdot 7 \quad 18 \cdot 2 \quad 0.0$

402

N.S.

N.S.

N.S.

N.S.

N.S.

N.S.

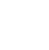

$44 \cdot 0$

$29 \cdot 0$

$\begin{array}{lllll}56 \cdot 8 & 20.0 & 23.2 & 0.0 & 375\end{array}$

$50.9 \quad 17.9$

$56 \cdot 5$

$19 \cdot 5$

$31 \cdot 1$

$24 \cdot 0$

0.0

636

N.S

(***) N.S.

N.S.

(c) Beacons Forest (SN 989180)

$\begin{array}{lllll}95.6 & 0.0 & 0.0 & 4.4 & 413\end{array}$

$96 \cdot$

6.3 -

$$
-
$$

(d) Rhossili Down (SS 416896)

$\begin{array}{ccc}\text { (d) Rhossiti } & \text { Down } \\ 1.8 & 21.4 & 271\end{array}$

$2 \cdot 4 \quad 26 \cdot 2 \quad 764$

764 N.S.

(e) Cantref (SN 992168)

$\begin{array}{ll}\text { Morph ratio } & 74 \\ \text { B. agrorum } & 74 \\ \text { B. lapponicus } & 71 \\ \text { B. lucorum } & 70 \cdot 5 \\ \text { B. pratorum } & \\ \quad(\text { ) } & \end{array}$

$74 \cdot 5 \quad 0 \cdot 0$

$\begin{array}{lrrccccr}0.0 & 25.5 & 699 & & & & & \\ - & 25.9 & 711 & \text { N.S. } & - & - & \text { N.S. } & 14.1 \\ - & 28.3 & 669 & \text { N.S. } & - & - & \text { N.S. } & 1.3 \\ - & 29.5 & 1147 & \left(^{*}\right) & - & - & * & 79.6 \\ - & 41.1 & 615 & (* * *) & - & - & * * * & 5.0\end{array}$

Morph ratio
B. agrorum

$58 \cdot 9$

(o)

B. agrorum

(o)

$\left(\sigma^{*}\right)$

B. lapidarius

(o)

B. lapponicus

$74 \cdot 1$

$71 \cdot 7$

$70 \cdot 5$

$\begin{array}{cc}0.0 & 0.0 \\ - & -\end{array}$

(f) Forest Lodge (SN 961247)

B. lucorum

$\begin{array}{lllll}36.0 & 0.0 & 0.0 & 64.0 & 356\end{array}$

$37 \cdot 3 \quad-\quad$ - $62 \cdot 7 \quad 416$

$416 \quad$ N.S.

N.S. - -

N.S.

$51 \cdot 7$

$37 \cdot 6 \quad-\quad-\quad 62 \cdot 4 \quad 431$

N.S.

$-\quad-$

N.S. $\quad 23 \cdot 0$

$26.3 \quad-\quad-\quad 73 \cdot 7$

646
433
362
618

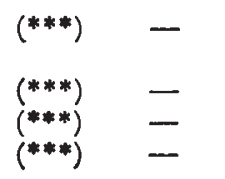

-

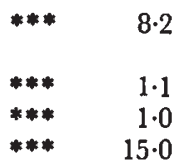

Morph and visit ratios listed as percentage values based on sample size $n$. Species frequency values, $f$, calculated from mean values on each day of observation.

Probability values calculated as described in text. Unbracketed probability values indicate morph types subject to preferential pollination, and bracketed values indicate morph types discriminated against.

$*$ = significant at 5 per cent level; $* *=$ significant at 1 per cent level; $* * *=$ significant at $0 \cdot 1$ per cent level. 
involved their preferential pollination whereas in nine cases they were discriminated against.

Several of the bee species which exhibited preferential pollination of the white morphs were present in quite high frequency in the populations in which they exhibited such behaviour. Their relative capacity for pollen transport was less clear but since the smaller species, which may be assumed to have lower pollen carrying capacity, appeared relatively more active it is possible that this may not be an important variable.

The degree of discrimination varied between species, between sexes and between the same sex in different populations. Whereas Bombus agrorum was uniformly non-discriminative in all populations, each of the other species displayed discrimination. The morph visit ratios of the two sexes of Bombus agrorum were not significantly different when the two sexes were scored separately at Forest Lodge, whereas those of the two sexes of $B$. lapidarius differed significantly in each of the three populations in which this species occurred $(\mathrm{P}<0.01$ in each case). The greatest differences between the sexes in this species occurred in the two populations in which the degrees of discrimination were greatest (Mynydd Llangattwg and Forest Lodge) and in both cases the females were the most discriminative $(P<0.001$ in each case $)$.

The highest intensity of foraging occurred on dry days that were calm and relatively warm. The proportion of different species foraging a population was not greatly affected by climatic fluctuation but in all populations the proportion of male bees was considerably higher towards the end of the summer.

Variation between populations in the proportions of the sexes may in part explain the differences in the discriminative behaviour of species between populations. However, other local influences appeared to be operative since the worker $B$. pratorum exhibited different discriminative patterns at Beacons Forest and Cantref, populations which were only half a mile apart. Discriminative behaviour might be related to such additional influences as the frequency and density of morph types, and light intensity.

\section{Discussion}

Conditions of limited pollination may be assumed to produce increased inbreeding. In such conditions any morph type with a higher selfcompatibility might produce higher seed yields; however, at least the purple and white morph types did not differ in self-compatibility. Secondly increased inbreeding would produce greater homozygosity, which at the flower colour loci would represent increase in the frequency of the white genotype. The same effect would be produced by a degree of assortative pollination among the white morphs necessarily imposed by their preferential pollination. The degree of assortative pollination would be modified by the relative distribution of morph types within populations, such as has been revealed by other work in this species in which the sequence of pollinator flights was shown to bear relation to an index of heterogeneity in morph distribution derived by an independent technique (Mogford, 1972). Assortative pollination would occur at all levels of pollinator abundance, together with a degree of general inbreeding which Bateman (1947) has pointed out as being present even in large populations as a consequence of the limitations of pollination distance and seed dispersal.

$33 / 2-\mathbf{R}$ 
However, despite the production of some inbreeding with respect to flower colour, it would be expected that the degree of general outbreeding of a morph type would be increased by preferential pollination in any situation of limited pollination. In addition, it may be considered on general grounds that the effect of outbreeding is to increase the fitness of a morph type. This was supported by the compatibility determinations, which although demonstrating that one generation of selfing did not lower the measured capacity for seed production nevertheless indicated that selfing was less efficient that cross-pollination in the production of viable seed. It may therefore be considered admissible that the localisation of the polymorphism on seacliffs and mountains is consistent with an increase in the relative fitness of the white morph type as a consequence of preferential pollination in conditions of limited pollination.

Further, it is probable that within a population increase in the frequency of white morphs would result in the attraction of higher numbers of pollinators or encourage foraging for longer periods. If this were so, then in conditions of limited pollination a polymorphic population would be more efficiently cross-pollinated than a monomorphic purple population in the same situation, and accordingly the polymorphism could be said to be adaptive at the population level. It may be cautioned, however, that in populations of Phlox pilosa, polymorphic for flower colour, there occurred differences in seed production between the morph types which were reversed at the population level, these differences being likely to represent differences in the attractiveness of the morphs to pollinators (Levin and Kerster, 1970).

The conclusions derived from the previous paper (Mogford, 1974) indicate that discriminative pollination is unlikely to be the only major factor operative upon the polymorphism. It remains necessary to invoke a climatic explanation of the type suggested in that paper to explain the low frequency of white morphs in mountain forests, for such is not consistent with the various types of evidence which indicate that white flowers may be relatively more attractive at low light intensity (Hulkkonen, 1928, quoted in Free and Butler, 1959; Anderson, 1936; Baker, 1961). Similarly, the inverse relationship between white frequency and exposure in seacliff populations is the converse of that expected from preferential pollination of the white morphs.

Further work on the polymorphism should include the identification of phenotype by pigment analyses, which would allow the resolution of any cryptic polymorphism and a more precise study of bee discrimination. In addition, pigment analyses together with further genetical studies would provide estimates of outbreeding rates from progeny analyses and hence an indication of the proportional importance of discriminative pollination in the maintenance of the polymorphism.

Acknowledgments.-May I thank Professor C. D. Darlington and Professor F. R. Whatley for providing facilities at the Oxford Botany School; Professor E. B. Ford and Dr H. B. D. Kettlewell for commenting on the results; Dr S. R. J. Woodell for advice during the research; and Dr K. R. Lewis for reading the paper in manuscript. The work was financed by the N.E.R.C. and the Royal Society. 


\section{REFERENCES}

ANDERson, E. 1936. Colour variation in eastern North American flowers as exemplified by Hepatica acutiloba. Rhodora, 38, 301-304.

BAKER, H. G. 1961. The adaptations of flowering plants to nocturnal and crepuscular pollinators. Q. Rev. Biol., 36, 64-73.

Bateman, A. J. 1947. Contamination in seed crops. 3. Relation with isolation distance. Heredity, Lond., 1, 303-336.

EISIKowItch, D., AND GALIL, J. 1971. Effect of wind on the pollination of Pancratium maritimum L. (Amaryllidaceae) by hawkmoths (Lepidoptera: Sphingidae). F. Anim. Ecol., 40, 673-678.

PREE, J. B., AND BUTLER, C. G. 1959. Bumblebees. Collins, London.

HAGERUP, o. 1950. Rain Pollination. Biol. Meddr., 18, 1-19.

HAGERUP, o. 1951. Pollination in the Faroes, in spite of rain and poverty of insects. Biol. Meddr., 18, 1-48.

HEINRICH, B. 1972. Temperature regulation in the bumblebee Bombus vagans; a field study. Science, $175,185-187$.

HULKKonEN, o. 1928. Zur biologie der südfinnischen Hummeln. Annls Univ. fenn. abo., Ser. $A, 3,1-81$.

KNUTH, P. 1908. Handbook of Flower Pollination (translated by J. R. Ainsworth Davis). O.U.P., Oxford.

LEVIN, D. A., AND KERSTER, H. W. 1970. Phenotypic dimorphism and populational fitness in Phlox. Evolution, Lancaster, Pa., 24, 128-134.

мгуамото, s. 1960. Observations on the behaviour of Bombus diversus Smith (Biological studies on Japanese bees, 13). Insectes soc., 7, 39-56.

MOGFoRD, D. J. 1972. The Ecological Genetics of Flower Colour Variation in Cirsium palustre. D.Phil. thesis, Univ. of Oxford.

MOGFORD, D. J. 1974. Flower colour polymorphism in Cirsium palustre 1. Heredity, 33, 241-256. MÜLLER, H. 1883. The Fertilisation of Flowers (translated by D'Arcy Thompson). MacMillan, London.

PRoctor, M., AND Yeo, P. 1973. The Pollination of Flowers. Collins, London.

SMALL, J. 1917. Irritability of the pollen-presentation mechanism in the Compositae. Ann. Bot., 31, 261-268.

wILLIS, J. C., AND BURKILl, x. H. 1895. Flowers and insects in Great Britain. Part 1. Ann. Bot., 9, 227-273.

WILlIs, J. C., AND BURKILl, I. H. 1903. Flowers and insects in Great Britain. Part 2. Observations on the natural orders Dipsaceae, Plumbaginaceae, Compositae, Umbelliferae and Cornacea, made in the Clova mountains. Ann. Bot., 17, 313-349.

wILson, G. P. 1929. Pollination of hardy fruits: insect visitors to fruit blossoms. Ann. appl. Biol., 16, 602-629. 